\title{
Smoking and gender modify the effect of TWIST on patient survival in head and neck squamous carcinoma
}

\author{
Yun Zhu ${ }^{1}$, Wenjuan Zhang ${ }^{1}$ and Ping Wang ${ }^{2,3}$ \\ ${ }^{1}$ Department of Otorhinolaryngology, Union Hospital, Tongji Medical College, Huazhong University of Science and Technology, \\ Wuhan, 430022, China \\ ${ }^{2}$ Department of Pediatrics, Union Hospital, Tongji Medical College, Huazhong University of Science and Technology, Wuhan, \\ 430022, China \\ ${ }^{3}$ Cancer Genetic Laboratory, Department of Molecular and Human Genetics, Baylor College of Medicine, Houston, TX, 77025, \\ USA \\ Correspondence to: Ping Wang, email: wang_ping00@yahoo.com \\ Keywords: prognosis, twist-related protein, carcinoma, male, smoking \\ Received: June 21, 2017 \\ Accepted: July 26, 2017 \\ Published: September 06, 2017 \\ Copyright: Zhu et al. This is an open-access article distributed under the terms of the Creative Commons Attribution License 3.0 \\ (CC BY 3.0), which permits unrestricted use, distribution, and reproduction in any medium, provided the original author and source \\ are credited.
}

\section{ABSTRACT}

Purpose: TWIST is a critical factor for predicting prognosis in several human cancers. Here, we study the prognostic significance of TWIST1 and TWIST2 in Head and Neck squamous cell carcinoma (HNSCC) as well as interactions of TWISTs with both gender and smoking in patient survival.

Methods: upper quartile normalized RNA-seq V2 RSEM values of TWIST1 and TWIST2 expressions were retrieved from a TCGA HNSCC dataset. Kaplan-Meier survival curves were used to assess the associations of TWIST1 and TWIST2 with patient survival, and multivariate Cox proportional hazards regression models were used to estimate the hazards ratios (HRs) and their $95 \%$ confidence intervals (CIs).

Results: Survival analyses showed that high TWIST1 expression was associated with a poor overall survival at a borderline significance level, while a superior but not statistically significant overall survival was observed in high TWIST2 expression. The multivariate Cox proportional hazards regression model showed a significantly elevated risk of death $(H R=1.37, p=0.038)$ in patients with high TWIST1 compared to low TWIST1, and a borderline significantly decreased risk of death $(\mathrm{HR}=0.74, \mathrm{p}=$ 0.055) in patients with high TWIST2 compared to low TWIST2. Further stratification analyses showed that increased risks of death were found significantly in male and borderline significantly in smoker patients with high TWIST1 compared to low one, and a significantly decreased risk of death in non-smoker patients with high TWIST2 compared to low one.

Conclusions: TWIST1 and TWIST2 are differentially associated with HNSCC patient survival. Gender and smoking could modify the effect of TWISTs on the risk of death in HNSCC patients.

\section{INTRODUCTION}

Head and neck cancer (HNC) is a heterogeneous disease that can involve multiple sites including oral cavity, nasopharynx, oropharynx, hypopharynx, larynx, paranasal sinuses and salivary glands. Head and neck squamous cell carcinoma (HNSCC) is the most common type, accounting for $90 \%$ of all $\mathrm{HNC}$ and ranking the sixth leading cancer by incidence worldwide [1]. Heavy use of tobacco and alcohol, human papillomavirus (HPV) infection and xenobiotic exposure are important risk factors for HNSCC $[2,3]$. This disease is highly curable 
with a 5-year survival rate approximately from $40 \%$ to $60 \%$ [4]. The survival rate could be up to $80 \%$ for HNSCC patients with a disease at early stage $[5,6]$. Metastasis and relapse, however, remain a clinical challenge in the management of HNSCCs.

Epithelial-mesenchymal transition (EMT) is a well-established critical mechanism for carcinoma metastasis. During this reprogramming process, epithelial cells acquire sufficient plasticity to become more motile and invasive $[7,8]$. Several transcription factors (EMTTFs) have been demonstrated critically involved in EMT regulation and TWIST is known as the principal inducer [9]. TWIST prompts EMT by repressing the expression of epithelial markers, such as E-cadherin, resulting in a loss of epithelial cell-cell adhesion and by upregulating the expressions of mesenchymal genes, such as N-Cadherin [10]. High expression of TWIST has been associated with aggressive tumor properties and poor survival in many cancers, including HNSCC, esophageal, and cervical SCC [11-13]. In mammals, there are two forms of TWIST, TWIST1 and TWIST2. The two isoforms share more than $90 \%$ sequence homology and structural similarity, have similar biochemical properties in vitro, and are co-expressed in many cell lines and tissues $[14,15]$. However, the two isoforms can function differentially in carcinoma metastasis. For example, TWIST2 was reported to inhibit tumor formation in certain types of cancer [16-19]. Therefore, it is necessary to identify the prognosis roles of each isoform specifically.

Heavy tobacco use is an important risk factor for HNSCC [2, 3]. Cigarette smoking has been shown to promote EMT via upregulating EMT-associated gene expressions including TWIST [20]. However, whether smoking is associated with poor prognosis of HNSCC is controversial. Some reports argue that smoking [21] has no significant effect on HNSCC survival. In contrast, some studies suggest smoking may result in a significantly increased death risk in HNSCC $[22,23]$.

Gender may be another risk factor for HNSCC. The newly diagnosed cases in men are nearly 3-folds of those in women [24, 25]. In addition, the mortality of HNSCC in men is almost 2-folds higher than in women $[24,25]$. However, a couple of studies did not found statistical difference between males and females in overall survival of HNSCC $[26,27]$. Therefore, the better insight concerning risk factors for HNSCC is clearly needed.

Given that a high mortality rate is observed in male HNSCC and that tobacco use can regulate EMT, we asked whether gender and smoking could modify the effect of TWIST1/2 on patient survival in HNSCC. Therefore, the aim of this study is to evaluate the association between TWIST1, TWIST2 and both the clinicopathologic characteristics and survival of HNSCC patients, and the interplay between TWIST and either gender or smoking in the survival outcome.

\section{RESULTS}

\section{Clinicopathologic characteristics of patients}

Table 1 shows the clinical and pathologic characteristics of the 522 patients in the study. The average age of the patients was 60.9 years old (range from 1990). The majority $(73.7 \%, \mathrm{n}=384)$ of patients were men, and 137 out of 521 were women. Of the patients, $88.1 \%$ were Caucasian, followed by African American (9.3\%), Asian (2.2\%) and American Native (0.4\%). Among all the patients, there were 117 non-smokers and 391 smokers. More than half of the patients $(n=284)$ had a stage IV disease, 105 stage III, 98 stage II and 20 stage I. There were $12.2 \%$ patients having a tumor with grade I, $58.8 \%$ with grade II and $29 \%$ with grade III. Tumors were mainly located at the tongue $(n=200)$ and pharynx $(n=135)$. In the patients, 490 were at M0 of metastasis stage and 26 at M1-MX stage. For the 183 patients who had postradiotherapy information available, 121 (66.1\%) received radiotherapy after surgery, while 62 did not. The average overall survival was 21.2 months with the range from 0.07 to 210.8 months for 519 patients with available followup information. During the follow-up, 222 of 521 patients with outcome information available died, 229 still lived at the end of the study, and the follow-up for the rest lost (or censored).

\section{TWIST1 and TWIST 2 expression and their associations with clinicopathologic features in patients}

The average expressions of TWIST1 and TWIST2 were 168.2 (range: 4.1 -6812) and 55 (range: 0.9 -407), respectively, in these patients (Table 1). Associations of TWIST1 and TWIST2 were analyzed and the results are shown in Table 2. TWIST1 and TWIST2 levels in female and male patients were almost identical $(\mathrm{p}=0.846$ for TWIST1 and $\mathrm{p}=0.856$ for TWIST2). No significant differences in TWIST1 or TWIST2 were found between Caucasian and other. Smokers (including ever and current smokers), however, had significantly higher levels of TWIST2 than non-smokers $(\mathrm{p}=0.015)$; while TWIST1 is not found different between the two groups. In addition, TWIST1 and TWIST2 levels were not significantly related to the stage of HDNC (I-IV). However,TWIST2 levels were significantly associated with tumor grade ( $p<0.0001)$ with the lowest levels in Grade III. Neither tumor location nor metastasis stage was associated with TWIST1 or TWIST2 expressions. Radiotherapy did not change TWIST1 or TWIST2 expression. 
Table 1: Characteristics of patients and gene expressions of TWIST1 and TWIST2

\begin{tabular}{|c|c|c|c|}
\hline Variable & $\mathbf{N}$ & $\%$ & Range \\
\hline Gender & 521 & & \\
\hline Female & 137 & 26.3 & \\
\hline Male & 384 & 73.7 & \\
\hline Race & 506 & & \\
\hline Caucasian & 446 & 88.1 & \\
\hline African American & 47 & 9.3 & \\
\hline Asian & 11 & 2.2 & \\
\hline American Native & 2 & 0.4 & \\
\hline Smoking & 508 & & \\
\hline No & 117 & 23.0 & \\
\hline Yes & 391 & 77.0 & \\
\hline Disease Stage & 507 & & \\
\hline I & 20 & 3.9 & \\
\hline II & 98 & 19.3 & \\
\hline III & 105 & 20.7 & \\
\hline IV & 284 & 56.1 & \\
\hline Tumor Grade & 517 & & \\
\hline I & 63 & 12.2 & \\
\hline II & 304 & 58.8 & \\
\hline III & 150 & 29.0 & \\
\hline Tumor site & 521 & & \\
\hline Tongue & 200 & 38.4 & \\
\hline Pharynx & 135 & 25.9 & \\
\hline other & 186 & 35.7 & \\
\hline Metastasis Stage & 516 & & \\
\hline M0 & 490 & 95.0 & \\
\hline M1-MX & 26 & 5.0 & \\
\hline Radiotherapy & 183 & & \\
\hline No & 62 & 33.9 & \\
\hline Yes & 121 & 66.1 & \\
\hline Death & 451 & & \\
\hline No & 229 & 57.4 & \\
\hline Yes & 222 & 42.6 & \\
\hline Age (Mean $\pm \mathrm{SD}^{*}$, years) & 520 & $60.9 \pm 11.9$ & $19-90$ \\
\hline Overall survival (months) & 519 & 21.2 & $0.07-210.8$ \\
\hline TWIST1 (Median) & 522 & 168.2 & $4.1-6812$ \\
\hline TWIST2 (Median) & 522 & 55 & $0.9-407$ \\
\hline
\end{tabular}

* SD: standard deviation. 
Table 2: Associations of TWIST1 and TWIST2 expressions with clinicopathologic variables

\begin{tabular}{|c|c|c|c|c|c|}
\hline \multirow[b]{2}{*}{ Variable } & \multirow[b]{2}{*}{$\mathbf{N}$} & \multicolumn{2}{|c|}{ TWIST1 } & \multicolumn{2}{|c|}{ TWIST2 } \\
\hline & & Mean (SD) ${ }^{1}$ & $p$ value & $\begin{array}{c}\text { Mean } \\
(\text { SD) }\end{array}$ & p value \\
\hline Gender & 521 & & 0.846 & & 0.856 \\
\hline Female & 137 & $2.20(0.33)$ & & $\begin{array}{c}1.70 \\
(0.37)\end{array}$ & \\
\hline Male & 384 & $2.19(0.39)$ & & $\begin{array}{c}1.69 \\
(0.42)\end{array}$ & \\
\hline Race & 506 & & 0.994 & & 0.688 \\
\hline Caucasian & 446 & $2.19(0.37)$ & & $\begin{array}{c}1.69 \\
(0.41)\end{array}$ & \\
\hline Other & 60 & $2.19(0.42)$ & & $\begin{array}{c}1.71 \\
(0.36)\end{array}$ & \\
\hline Smoking & 508 & & 0.377 & & 0.015 \\
\hline No & 117 & $2.22(0.34)$ & & $\begin{array}{c}1.62 \\
(0.44)\end{array}$ & \\
\hline Yes & 391 & $2.18(0.38)$ & & $\begin{array}{c}1.72 \\
(0.39)\end{array}$ & \\
\hline Disease Stage & 507 & & 0.417 & & 0.266 \\
\hline I & 20 & $2.13(0.28)$ & & $\begin{array}{c}1.85 \\
(0.36)\end{array}$ & \\
\hline II & 98 & $2.16(0.41)$ & & $\begin{array}{c}1.72 \\
(0.39)\end{array}$ & \\
\hline III & 105 & $2.16(0.39)$ & & $\begin{array}{c}1.69 \\
(0.42)\end{array}$ & \\
\hline IV & 284 & $2.22(0.37)$ & & $\begin{array}{c}1.68 \\
(0.40)\end{array}$ & \\
\hline Tumor Grade & 517 & & 0.275 & & $<0.0001$ \\
\hline I & 63 & $2.12(0.32)$ & & $\begin{array}{c}1.72 \\
(0.36)\end{array}$ & \\
\hline II & 304 & $2.20(0.37)$ & & $\begin{array}{c}1.76 \\
(0.37)\end{array}$ & \\
\hline III & 150 & $2.21(0.42)$ & & $\begin{array}{c}1.57 \\
(0.45)\end{array}$ & \\
\hline Tumor site & 521 & & 0.156 & & 0.107 \\
\hline Tongue & 200 & $2.19(0.37)$ & & $1.65(0.43)$ & \\
\hline Pharynx & 135 & $2.14(0.41)$ & & $1.74(0.36)$ & \\
\hline other & 186 & $2.22(0.35)$ & & $1.71(0.40)$ & \\
\hline Metastasis Stage & 516 & & 0.693 & & 0.348 \\
\hline M0 & 490 & $2.19(0.37)$ & & $\begin{array}{c}1.70 \\
(0.40)\end{array}$ & \\
\hline
\end{tabular}

(Continued) 


\begin{tabular}{|c|c|c|c|c|c|}
\hline \multirow[b]{2}{*}{ Variable } & \multirow[b]{2}{*}{$\mathbf{N}$} & \multicolumn{2}{|c|}{ TWIST1 } & \multicolumn{2}{|c|}{ TWIST2 } \\
\hline & & Mean $\left(\right.$ SD) ${ }^{1}$ & $p$ value & $\begin{array}{l}\text { Mean } \\
\text { (SD) }\end{array}$ & $p$ value \\
\hline M1-MX & 26 & $2.16(0.52)$ & & $\begin{array}{c}1.62 \\
(0.43)\end{array}$ & \\
\hline Radiotherapy & 183 & & 0.118 & & 0.304 \\
\hline No & 62 & $2.15(0.41)$ & & $1.73(0.40)$ & \\
\hline Yes & 121 & $2.25(0.41)$ & & $1.67(0.38)$ & \\
\hline
\end{tabular}

${ }^{1}$ Mean(SD): mean (standard deviation) in $\log 10$.

\section{Associations of TWIST1 and TWIST2 with patient survival}

To examine the associations of TWIST1 and TWIST2 gene expression with overall survival, we first performed Kaplan-Meier survival curves analyses stratified by either TWIST1 or TWIST2 expression levels. The results showed that patients with high TWIST1 levels had inferior overall survival than those with low TWIST1 (log-rank $\mathrm{p}$ $=0.076)($ Figure $1 \mathrm{~A})$. The medians overall survival were 47.9 months (95\% CI: $28.0-67.8$ months) for those with high TWIST1 and 56.9 months (95\% CI: $48.2-84.4$ months) for those with low TWIST1, respectively. The medians of overall survival were 52.3 months $(95 \% \mathrm{CI}$ : $45.9-100.5$ months) for those with high TWIST2 and 56.9 months (95\% CI: 35.5 - 69.7 months) for those with low TWIST2, respectively. However, the survival curves were markedly separated with the superior overall survival for patients with high TWIST2 after approximately 60 months compared to those with low. No statistically significant association was found between TWIST2 expression and overall survival (Figure 1B, log-rank $p=0.107$ ).

Since gender and smoking status have effects on HNSCC [24, 25], we then checked the associations of TWIST1 and TWIST2 expression levels with overall survival in subgroups of either gender or smoking status. We found that in the subgroups of males and smokers, patients with high TWISTI had worse survival than those with low TWIST1. In male patients with high TWIST1, the median overall survival was 52.3 months $(95 \%$ CI: $28.3-$ 67.8 months), whereas in male patients with low TWIST1, the median survival was 68.4 months $(95 \%$ CI: $54.9-$ 95.3 months) (Figure 2A, log-rank $\mathrm{p}=0.011$ ). In smoker patients with high TWIST1, the median overall survival was 47.0 months (95\% CI: $28.3-65.8$ months), whereas in smoker patients with low TWIST1, the median survival was 64.8 months (95\% CI: 45.9 - 156.4 months) (Figure $2 \mathrm{~B}, \log$-rank $\mathrm{p}=0.024)$. However, in the subgroups of either female or non-smokers, no statistically significant association was found between TWIST1 expression and overall survival (data not shown). In the subgroup of nonsmoker patients, those with low TWIST2 expression had inferior overall survival, compared with those with high TWIST2 ( $\log$ rank $\mathrm{p}=0.004)$ (Figure $2 \mathrm{C}$ ); the survival rate did not reach 0.5 for the group with high TWIST2, and the median of overall survival was $\infty(95 \%$ CI: $49.4-\infty$ months) for high TWIST2. In contrast, the median survival time for the group with low TWIST2 was 35.5 months (95\% CI: 19.0 - 68.4 months). However, no statistically significant associations were found between TWIST2 and overall survival in the subgroups of smoker patients, or male or female patients (data not shown).

We further performed multivariate Cox proportional hazard models to validate the Kaplan-Meier survival curves analyses with the adjustment of potential confounding variables and stratified by either gender or smoking status. Similarly, the multivariate Cox analysis showed that high TWIST1 increased the risk of death, while high TWIST2 decreased the risk of death (Table $3)$. The HRs were 1.37 (95\% CI: $1.02-1.84)$ for high TWIST1 in comparison to low one $(\mathrm{p}=0.038)$, and 0.74 (95\% CI: $0.55-1.01$ ) for high TWIST2 compared to low one $(\mathrm{p}=0.055)$ with the adjustment of patients' age at diagnosis, disease stage, tumor grade, tumor site, gender and smoking status. When patients were stratified by either gender or smoking status, those with high TWISTI had significantly elevated risk of death compared to those with low TWIST1 in male (HR $=1.59,95 \%$ CI: $1.12-2.25)(\mathrm{p}$ $=0.010)$ and borderline significant elevated risk in smoker $(\mathrm{HR}=1.38,95 \% \mathrm{CI}: 0.99-1.94)(\mathrm{p}=0.058)$ subgroups (Table 4) after adjusting covariates. In nonsmokers, patients with high TWIST2 had significantly decreased risk of death compared to those with low one; the adjusted HR was $0.38(95 \%$ CI: $0.18-0.80)(\mathrm{p}=0.011)$. However, when we stratified the patients with either TWIST1 or TWIST2 levels, we observed that there were no significant associations between either gender or smoking status and the risk of death in the multivariate Cox proportional hazard analyses (data not shown). 

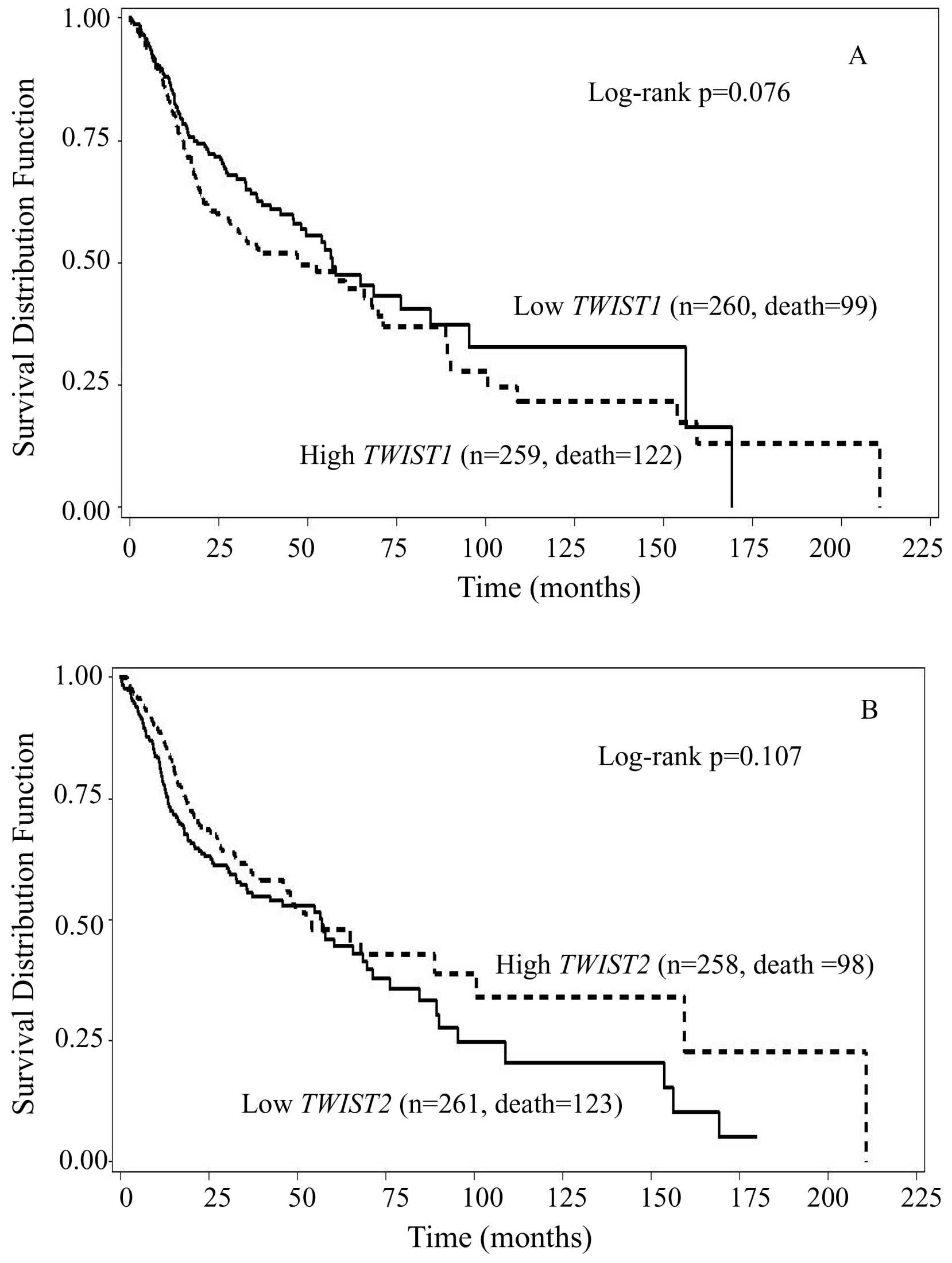

Figure 1: Kaplan-Meier overall survival curves stratified by either TWIST1 (A) or TWIST2 (B) expression levels. In comparison to low expression, High TWIST1 expression had inferior overall survival (log-rank p =0.076), while high TWIST2 had slightly but not statistically significant superior but overall survival at the beginning and after 60 months of follow-up (log-rank $\mathrm{p}=0.107)$. 

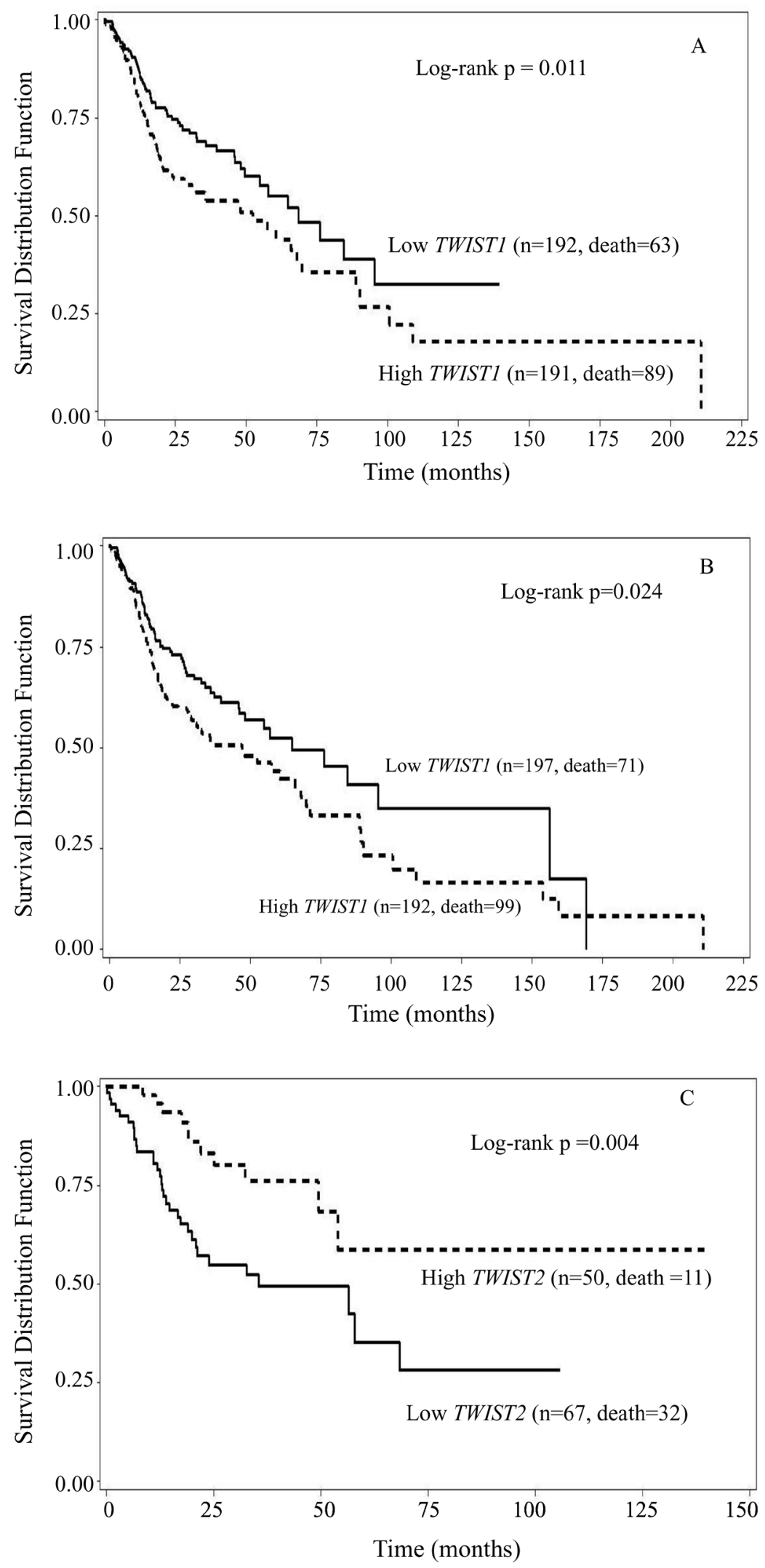

Figure 2: Kaplan-Meier overall survival curves stratified by either TWIST1 or TWIST2 in the subgroup of gender and smoking status. High TWISTl had significantly inferior overall survival than low TWISTl in male patients (A) $(\log$-rank $\mathrm{p}=0.011)$, and smoker patients $(\mathbf{B})(\log$-rank $\mathrm{p}=0.024)$ compared to low TWIST1, respectively. In nonsmoker patients, high TWIST2 had significantly superior overall survival in comparison to low one $(\mathbf{C})(\log -\operatorname{rank} \mathrm{p}=0.004)$. 
Table 3: Associations of TWIST1 and TWIST2 expressions with the risk of death

\begin{tabular}{llcc}
\hline Variable & HR $^{\mathbf{1}}$ & $\mathbf{9 5 \%} \mathbf{C I}^{\mathbf{2}}$ & p value \\
\hline TWIST1 (high vs low) & 1.37 & $1.02-1.84$ & 0.038 \\
TWIST2 (high vs low) & 0.74 & $0.55-1.01$ & 0.055 \\
Smoking (yes vs no) & 1.17 & $0.81-1.68$ & 0.403 \\
Gender (male vs female) & 0.87 & $0.63-1.20$ & 0.406 \\
Age (per 5 years) & 1.10 & $1.02-1.18$ & 0.010 \\
Stage & 1.06 & $0.90-1.25$ & 0.459 \\
Grade & 1.02 & $0.82-1.26$ & 0.886 \\
Tumor site & & & 0.865 \\
Tongue & 1.00 & & 0.345 \\
Pharynx & 0.97 & $0.84-1.67$ & \\
Other & 1.18 & 0.44 & \\
\hline
\end{tabular}

${ }^{1} \mathrm{HR}$, hazard ratio, which was estimated in multivariate Cox proportional hazard regression analysis.

${ }^{2} \mathrm{CI}$ : confidence interval.

\section{DISCUSSION}

In this study, we demonstrated the associations of the two isoforms of a critical EMT regulators, TWIST1 and TWIST2, with clinicopathological characteristics and overall survival in HNSCC and their interactions with either gender or smoking in the risk of death using a publicly accessed TCGA Head and Neck squamous cell carcinoma dataset. We found that TWIST1, but not TWIST2, was significantly positively linked to overall survival of these patients. Further analysis stratified with gender and tobacco use revealed this significant correlation only existing in males or smokers but not significantly in female or non-smokers. Unexpectedly, although TWIST2 levels were not significantly related with overall survival, higher TWIST2 levels were correlated with lower grade in overall patients and better survival in non-smokers; interestingly, this beneficial relation of TWIST2 with survival is lost in smokers.

Generally, disease stage and age are important unfavorable prognostic marker in human cancer. Unexpectedly, disease stage was not significantly associated with the risk of death in this study. However, we did find that patients' age at diagnosis increased the mortality of HNSCC. These results suggest that the finding might not result from by chance. In addition, we could not rule out the possibility that the sample size in early stage (stage I: 20/507; stage II: 98/507) was relatively small, while the majority of patients were diagnosed at advanced stage in this study, which might result in insufficient power to detect an association between disease stage and risk of death. Furthermore, more than $25 \%$ of stage I and II oral cavity cancer patients can develop recurrence, a culprit of death [28].

To our knowledge, this is the first study to evaluate the respective role of TWIST1 and TWIST2 in HNSCC with a relatively large sample size. Unlike many studies which include patients who were followed up to 36 or 70 months, as long as up to 210.8 months were followed up for the patients.

Since TWISTs were reported as the master regulator in tumor metastasis in 2004 [29], multiple studies have demonstrated TWIST as a potential prognostic marker for many cancers, including myeloid leukemia, oral, esophageal, lung, breast, cervical and bladder cancer [27, 30-34]. TWIST enhances carcinoma metastasis by promoting cell proliferation, migration, invasion and colony formation. High TWIST protein expression has been shown in a positive correlation with poor prognosis in many cancers, including HNSCC [7, 26, 27, 35-37]. TWIST1 and TWIST2 share more than $90 \%$ sequence homology and structural similarity, and they have similar biochemical properties in vitro, and overlap in localization and expression pattern $[14,15,38]$. Thus, it was thought that overexpression of TWIST1 and/or TWIST2 was similarly correlated to poor prognosis in HNSCCs [36, 37]. In several meta-analysis studies, TWIST1 and TWIST2 were treated as identical and the data were combined together [27, 39]. However, there is evidence indicating that the two isoforms function differentially in carcinoma metastasis [40]. For example, the prognostic value of TWIST1 has been consistently demonstrated in many cancers; while although TWIST2 was also a prognostic marker in certain types of cancer, it was not associated with invasion and metastasis in hepatocellular 
Table 4: Associations of TWIST1 and TWIST2 expressions with the risk of death stratified by either gender or smoking status

\begin{tabular}{lcccc}
\hline Stratefied variabel & Variable & adj-HR $^{\mathbf{1}}$ & $\mathbf{9 5 \%} \mathbf{C I}^{\mathbf{2}}$ & p value \\
\hline Gender $^{3}$ & & & & \\
Female & TWIST1 (high vs low) & 1.07 & $0.61-1.88$ & 0.802 \\
& TWIST2 (high vs low & 0.68 & $0.38-1.20$ & 0.181 \\
Male & TWIST1 (high vs low) & 1.59 & $1.12-2.25$ & 0.010 \\
& TWIST2 (high vs low) & 0.74 & $0.51-1.05$ & 0.094 \\
Smoking status & & & & \\
No & TWIST1 (high vs low) & 0.67 & $0.32-1.44$ & 0.309 \\
& TWIST2 (high vs low & 0.38 & $0.18-0.80$ & 0.011 \\
Yes & TWIST1 (high vs low) & 1.38 & $0.99-1.94$ & 0.058 \\
& TWIST2 (high vs low) & 0.90 & $0.64-1.27$ & 0.559 \\
\hline
\end{tabular}

'adj-HR: adjusted hazard ratio, which was estimated in multivariate Cox proportional hazard regression analyses.

${ }^{2} \mathrm{CI}$ : confidence interval.

${ }^{3}$ covariates included patient age (per 5 years), disease stage, tumor grade, smoking status and tumor site.

${ }^{4}$ covariates included patient age (per 5 years), disease stage, tumor grade, gender, and tumor site.

carcinoma [16]. Moreover, TWIST2 was reported to inhibit tumor formation in a mouse osteosarcoma model [17]. In acute lymphoblastic leukemia, overexpression of TWIST2 inhibits cell growth, prompts apoptosis and increases sensitivity to chemotherapeutic agents [18]. TWIST2 may act as a tumor repressor by activating known tumor-suppressor genes [17, 19]. Indeed, the prognostic value of TWIST in HNSCC is still controversial or even opposite. Some paper reported the association of TWIST1 with poor prognosis in ESCC patients [12, 41, 42]; whereas there are also studies showing that TWIST is not associated with EMT of esophageal adenocarcinoma [43-45]. In our study, we found that higher TWIST1 was associated with poor survival and this relationship was more noticeable in smokers or males; unexpectedly, higher TWIST2 indicates a better survival in non-smokers. Based on the findings in this study, TWISTI showed a risk factor increasing the mortality in HNSCC, particularly in male patients, whereas TWIST2 exhibited a protective role in decreasing the mortality in HNSCC, particularly in nonsmoker patients.

In our study, we analyzed whether gender and smoking could modify the effect of TWISTI/2 levels on the risk of death in HNSCC patients. In consistent with other studies [26, 27], our analysis did not find an impact of either gender or smoking on the risk of death. In addition, TWIST1 expression was not associated with gender in this study, which is in the agreement with the other previous results that TWIST expression was not related to gender in nasopharyngeal cancer [26]. However, we found that higher TWIST1 was linked to poor survival only in males but not in females. Taken together, our study firstly suggests that gender might be a modifier rather than a confounder in the effect of TWIST1 expression on patient survival in HNSCC.

Smoking is a known primary risk factors for HNSCC $[46,47]$, and tobacco use is reported in correlation with higher TWIST expression. Benzo(a)pyrene (BaP), one of the major chemical substance in cigarette, was found to enhances cell migration and invasion as well as TWIST expression in non-small cell lung cancer (NSCLC) cell line A549. In addition, the knockdown of TWIST blocked the migration and invasion of A549 cells induced by BaP [48], implying that smoking may cause EMT through TWIST. Our study revealed that the mRNA levels of TWIST1 were not affected by smoking. This is in consistent with study from the other lab [49]. However, the inverse relationship of TWISTI with survival becomes even more noticeable in smokers. Interestingly, although TWIST2 level is slightly higher in smokers than in non-smokers, the beneficial role of TWIST2 on survival rate is still lost in smokers. These data suggest that smoking may modify the effect of TWIST2 expression on the patient survival in HNSCC.

In summary, this study revealed that TWIST1 and TWIST2 were differently involved in prognostic of HNSCC with high TWIST1 linking to poor survival, which is more obvious in either males or smokers than in either female or non-smokers. In addition, high TWIST2 seems to decrease the risk of death in non-smoker but not in smoker patients. These findings suggest TWIST1 and TWIST2 are potential prognostic markers of HNSCC, and gender and smoking status can modify the effect of TWIST1 and TWIST2 expression on the risk of death in HNSCC. 


\section{MATERIALS AND METHODS}

\section{Gene expression and clinicopathologic data}

We retrieved upper quartile normalized RNA-seq V2 RSEM values of TWIST1 and TWIST2 expressions from a TCGA Head and Neck squamous cell carcinoma dataset, which is available at TCGA provisional (http:// www.cbioportal.org/). Experimental data generation and processing were conducted as previously described [50]. After downloading clinicopathologic data on these patients, we assembled gene expressions and clinicopathologic data for data analyses.

\section{Statistical analyses}

Statistical analyses were performed using SAS version 9.2 (SAS Institute, inc). The overall survival in months was calculated as the time from surgery until the occurrence of death. General linear models (GLM) were used to analyze the associations of TWISTI and TWIST2 with clinicopathologic features and general characteristics of patients, in which the expressions of TWIST1 and TWIST2 were further converted by logarithm. The logarithm conversion was made after one plus each of the values to avoid impossible conversion for those with a value of zero. The median of either TWIST1 or TWIST2 expression levels was used as a cutoff value in classifying patients into two groups, low or high, in survival analyses. Kaplan-Meier survival curves were used to assess the associations of TWIST genes with patient survival, and multivariate Cox proportional hazards regression models were used to estimate the hazards ratios (HRs) and their $95 \%$ confidence intervals (95\% CIs) with the adjustment for patients' age at diagnosis, disease stage, tumor grade, gender, smoking status and tumor site. A p value of less than 0.05 was considered statistically significant.

\section{ACKNOWLEDGMENTS}

The manuscript was written through contributions of all authors. All authors accepted the final version of this manuscript. This work was funded by National Natural Science Foundation of China (No. 81600805).

\section{CONFLICTS OF INTEREST}

The authors declare no conflicts of interest.

\section{REFERENCES}

1. Ferlay J, Soerjomataram I, Dikshit R, Eser S, Mathers C, Rebelo M, Parkin DM, Forman D, Bray F. Cancer incidence and mortality worldwide: sources, methods and major patterns in GLOBOCAN 2012. Int J Cancer. 2015; 136:E359-86. https://doi.org/10.1002/ijc.29210.
2. Sturgis EM, Cinciripini PM. Trends in head and neck cancer incidence in relation to smoking prevalence: an emerging epidemic of human papillomavirus-associated cancers? Cancer. 2007; 110:1429-35. https://doi.org/10.1002/ cncr. 22963.

3. Marur S, D'Souza G, Westra WH, Forastiere AA. HPVassociated head and neck cancer: a virus-related cancer epidemic. Lancet Oncol. 2010; 11:781-9. https://doi. org/10.1016/S1470-2045(10)70017-6.

4. Grégoire V, Lefebvre JL, Licitra L, Felip E, and EHNSESMO-ESTRO Guidelines Working Group. Squamous cell carcinoma of the head and neck: EHNS-ESMO-ESTRO Clinical Practice Guidelines for diagnosis, treatment and follow-up. Ann Oncol. 2010; 21:v184-6. https://doi. org/10.1093/annonc/mdq185.

5. Holmes JD, Dierks EJ, Homer LD, Potter BE. Is detection of oral and oropharyngeal squamous cancer by a dental health care provider associated with a lower stage at diagnosis? J Oral Maxillofac Surg. 2003; 61:285-91. https:// doi.org/10.1053/joms.2003.50056.

6. O'Sullivan E. Improving early diagnosis of oral cancer. J Oral Maxillofac Surg. 2004; 62: 115.

7. Jouppila-Matto A, Narkio-Makela M, Soini Y, Pukkila M, Sironen R, Tuhkanen H, Mannermaa A, Kosma VM. Twist and snail expression in pharyngeal squamous cell carcinoma stroma is related to cancer progression. BMC Cancer. 2011; 11:350. https://doi.org/10.1186/1471-2407-11-350.

8. Watanabe O, Imamura H, Shimizu T, Kinoshita J, Okabe T, Hirano A, Yoshimatsu K, Konno S, Aiba M, Ogawa $\mathrm{K}$. Expression of twist and wnt in human breast cancer. Anticancer Res. 2004; 24:3851-6.

9. Yang J, Mani SA, Donaher JL, Ramaswamy S, Itzykson RA, Come C, Savagner P, Gitelman I, Richardson A, Weinberg RA. Twist, a master regulator of morphogenesis, plays an essential role in tumor metastasis. Cell. 2004; 117:927-39. https://doi.org/10.1016/j.cell.2004.06.006.

10. Cano A, Perez-Moreno MA, Rodrigo I, Locascio A, Blanco MJ, del Barrio MG, Portillo F, Nieto MA. The transcription factor snail controls epithelial-mesenchymal transitions by repressing E-cadherin expression. Nat Cell Biol. 2000; 2:76-83. https://doi.org/10.1038/35000025.

11. Yang $\mathrm{MH}, \mathrm{Wu}$ MZ, Chiou SH, Chen PM, Chang SY, Liu CJ, Teng SC, Wu KJ. Direct regulation of TWIST by HIF1alpha promotes metastasis. Nat Cell Biol. 2008; 10:295305. https://doi.org/10.1038/ncb1691.

12. Sasaki K, Natsugoe S, Ishigami S, Matsumoto M, Okumura H, Setoyama T, Uchikado Y, Kita Y, Tamotsu K, Sakamoto A, Owaki T, Aikou T. Significance of Twist expression and its association with E-cadherin in esophageal squamous cell carcinoma. J Exp Clin Cancer Res. 2009; 28:158. https:// doi.org/10.1186/1756-9966-28-158.

13. Shibata K, Kajiyama H, Ino K, Terauchi M, Yamamoto E, Nawa A, Nomura S, Kikkawa F. Twist expression in patients with cervical cancer is associated with poor 
disease outcome. Ann Oncol. 2008; 19:81-5. https://doi. org/10.1093/annonc/mdm344.

14. Li L, Cserjesi P, Olson EN. Dermo-1: a novel twistrelated bHLH protein expressed in the developing dermis. Dev Biol. 1995; 172:280-92. https://doi.org/10.1006/ dbio.1995.0023.

15. Mudry JM, Massart J, Szekeres FL, Krook A. TWIST1 and TWIST2 regulate glycogen storage and inflammatory genes in skeletal muscle. J Endocrinol. 2015; 224:303-13. https:// doi.org/10.1530/JOE-14-0474.

16. Liu AY, Cai Y, Mao Y, Lin Y, Zheng H, Wu T, Huang Y, Fang X, Lin S, Feng Q, Huang Z, Yang T, Luo Q, et al. Twist2 promotes self-renewal of liver cancer stem-like cells by regulating CD24. Carcinogenesis. 2014; 35:53745. https://doi.org/10.1093/carcin/bgt364.

17. Ishikawa $\mathrm{T}$, Shimizu $\mathrm{T}$, Ueki A, Yamaguchi SI, Onishi N, Sugihara E, Kuninaka S, Miyamoto T, Morioka H, Nakayama R, Kobayashi E, Toyama Y, Mabuchi Y, et al. Twist2 functions as a tumor suppressor in murine osteosarcoma cells. Cancer Sci. 2013; 104:880-8. https:// doi.org/10.1111/cas.12163.

18. Thathia SH, Ferguson S, Gautrey HE, van Otterdijk SD, Hili M, Rand V, Moorman AV, Meyer S, Brown R, Strathdee G. Epigenetic inactivation of TWIST2 in acute lymphoblastic leukemia modulates proliferation, cell survival and chemosensitivity. Haematologica. 2012; 97: 371-8. https://doi.org/10.3324/haematol.2011.049593.

19. Zhang X, Ma W, Cui J, Yao H, Zhou H, Ge Y, Xiao L, Hu X, Liu BH, Yang J, Li YY, Chen S, Eaves CJ, et al. Regulation of p21 by TWIST2 contributes to its tumor-suppressor function in human acute myeloid leukemia. Oncogene. 2015; 34:3000-10. https://doi.org/10.1038/onc.2014.241.

20. Yoshino I, Kometani T, Shoji F, Osoegawa A, Ohba T, Kouso H, Takenaka T, Yohena T, Maehara Y. Induction of epithelial-mesenchymal transition-related genes by benzo[a]pyrene in lung cancer cells. Cancer. 2007; 110:36974. https://doi.org/10.1002/cncr.22728.

21. Lopez RV, Zago MA, Eluf-Neto J, Curado MP, Daudt AW, da Silva-Junior WA, Zanette DL, Levi JE, de Carvalho MB, Kowalski LP, Abrahao M, de Gois-Filho JF, Boffetta P, et al. Education, tobacco smoking, alcohol consumption, and IL-2 and IL-6 gene polymorphisms in the survival of head and neck cancer. Braz J Med Biol Res. 2011; 44:1006-12.

22. Sharp L, McDevitt J, Carsin AE, Brown C, Comber H. Smoking at diagnosis is an independent prognostic factor for cancer-specific survival in head and neck cancer: findings from a large, population-based study. Cancer Epidemiol Biomarkers Prev. 2014; 23:2579-90. https://doi. org/10.1158/1055-9965.EPI-14-0311.

23. Mayne ST, Cartmel B, Kirsh V, Goodwin WJ Jr. Alcohol and tobacco use prediagnosis and postdiagnosis, and survival in a cohort of patients with early stage cancers of the oral cavity, pharynx, and larynx. Cancer Epidemiol Biomarkers Prev. 2009; 18:3368-74. https://doi.org/10.1158/1055-9965. EPI-09-0944.
24. Chen W, Zheng R, Baade PD, Zhang S, Zeng H, Bray F, Jemal A, Yu XQ, He J. Cancer statistics in China, 2015. CA Cancer J Clin. 2016; 66:115-32. https://doi.org/10.3322/ caac. 21338.

25. Siegel RL, Miller KD, Jemal A. Cancer Statistics, 2017. CA Cancer J Clin. 2017; 67:7-30. https://doi.org/10.3322/ caac. 21387.

26. Zhuo X, Chang A, Huang C, Yang L, Xiang Z, Zhou Y. Expression of TWIST, an inducer of epithelialmesenchymal transition, in nasopharyngeal carcinoma and its clinical significance. Int J Clin Exp Pathol. 2014; 7:8862-8.

27. Zhuo X, Luo H, Chang A, Li D, Zhao H, Zhou Q. Is overexpression of TWIST, a transcriptional factor, a prognostic biomarker of head and neck carcinoma? Evidence from fifteen studies. Sci Rep. 2015; 5:18073. https://doi.org/10.1038/srep18073.

28. Brandwein-Gensler M, Smith RV. Prognostic indicators in head and neck oncology including the new 7th edition of the AJCC staging system. Head Neck Pathol. 2010; 4:53-61. https://doi.org/10.1007/s12105-010-0161-y.

29. Kang Y, Massague J. Epithelial-mesenchymal transitions: twist in development and metastasis. Cell. 2004; 118:277-9. https://doi.org/10.1016/j.cell.2004.07.011.

30. Hosono S, Kajiyama H, Terauchi M, Shibata K, Ino K, Nawa A, Kikkawa F. Expression of Twist increases the risk for recurrence and for poor survival in epithelial ovarian carcinoma patients. Br J Cancer. 2007; 96:314-20. https:// doi.org/10.1038/sj.bjc.6603533.

31. Lee KW, Kim JH, Han S, Sung CO, Do IG, Ko YH, Um $\mathrm{SH}$, Kim SH. Twist1 is an independent prognostic factor of esophageal squamous cell carcinoma and associated with its epithelial-mesenchymal transition. Ann Surg Oncol. 2012; 19:326-35. https://doi.org/10.1245/s10434-011-1867-0.

32. Wang N, Guo D, Zhao YY, Dong CY, Liu XY, Yang BX, Wang SW, Wang L, Liu QG, Ren Q, Lin YM, Ma XT. TWIST-1 promotes cell growth, drug resistance and progenitor clonogenic capacities in myeloid leukemia and is a novel poor prognostic factor in acute myeloid leukemia. Oncotarget. 2015; 6:20977-92. https://doi.org/10.18632/ oncotarget.4007.

33. Wushou A, Hou J, Zhao YJ, Shao ZM. Twist-1 up-regulation in carcinoma correlates to poor survival. Int J Mol Sci. 2014; 15:21621-30. https://doi.org/10.3390/ijms151221621.

34. Zhou Y, Liao Q, Han Y, Chen J, Liu Z, Ling H, Zhang J, Yang W, Oyang L, Xia L, Wang L, Wang H, Xue L, et al. Rac1 overexpression is correlated with epithelial mesenchymal transition and predicts poor prognosis in nonsmall cell lung cancer. J Cancer. 2016; 7:2100-9. https://doi. org/10.7150/jca.16198.

35. Ou DL, Chien HF, Chen CL, Lin TC, Lin LI. Role of Twist in head and neck carcinoma with lymph node metastasis. Anticancer Res. 2008; 28:1355-9. 
36. Gasparotto D, Polesel J, Marzotto A, Colladel R, Piccinin S, Modena P, Grizzo A, Sulfaro S, Serraino D, Barzan L, Doglioni C, Maestro R. Overexpression of TWIST2 correlates with poor prognosis in head and neck squamous cell carcinomas. Oncotarget. 2011; 2:1165-75. https://doi. org/10.18632/oncotarget.390.

37. da Silva SD, Alaoui-Jamali MA, Soares FA, Carraro DM, Brentani HP, Hier M, Rogatto SR, Kowalski LP. TWIST1 is a molecular marker for a poor prognosis in oral cancer and represents a potential therapeutic target. Cancer. 2014; 120: 352-62. https://doi.org/10.1002/cncr.28404.

38. Puisieux A, Valsesia-Wittmann S, Ansieau S. A twist for survival and cancer progression. Br J Cancer. 2006; 94:137. https://doi.org/10.1038/sj.bjc.6602876.

39. Zhang P, Hu P, Shen H, Yu J, Liu Q, Du J. Prognostic role of Twist or Snail in various carcinomas: a systematic review and meta-analysis. Eur J Clin Invest. 2014; 44:1072-94. https://doi.org/10.1111/eci.12343.

40. Franco HL, Casasnovas J, Rodriguez-Medina JR, Cadilla CL. Redundant or separate entities?--roles of Twist1 and Twist 2 as molecular switches during gene transcription. Nucleic Acids Res. 2011; 39:1177-86. https://doi. org/10.1093/nar/gkq890.

41. Yuen HF, Chan YP, Chan KK, Chu YY, Wong ML, Law SY, Srivastava G, Wong YC, Wang X, Chan KW. Id-1 and Id-2 are markers for metastasis and prognosis in oesophageal squamous cell carcinoma. Br J Cancer. 2007; 97:1409-15. https://doi.org/10.1038/sj.bjc.6604035.

42. Xie F, Li K, Ouyang X. Twist, an independent prognostic marker for predicting distant metastasis and survival rates of esophageal squamous cell carcinoma patients. Clin Exp Metastasis. 2009; 26:1025-32. https://doi.org/10.1007/ s10585-009-9292-5.

43. Ansieau S, Bastid J, Doreau A, Morel AP, Bouchet BP, Thomas C, Fauvet F, Puisieux I, Doglioni C, Piccinin S, Maestro R, Voeltzel T, Selmi A, et al. Induction of EMT by twist proteins as a collateral effect of tumor-promoting inactivation of premature senescence. Cancer Cell. 2008; 14:79-89. https://doi.org/10.1016/j.ccr.2008.06.005.

44. Horikawa T, Yang J, Kondo S, Yoshizaki T, Joab I, Furukawa M, Pagano JS. Twist and epithelial-mesenchymal transition are induced by the EBV oncoprotein latent membrane protein 1 and are associated with metastatic nasopharyngeal carcinoma. Cancer Res. 2007; 67: 1970-8. https://doi.org/10.1158/0008-5472.CAN-06-3933.

45. Jethwa P, Naqvi M, Hardy RG, Hotchin NA, Roberts S, Spychal R, Tselepis C. Overexpression of Slug is associated with malignant progression of esophageal adenocarcinoma. World J Gastroenterol. 2008; 14:1044-52.

46. Kim L, King T, Agulnik M. Head and neck cancer: changing epidemiology and public health implications. Oncology (Williston Park). 2010; 24:915-9, 24.

47. Andre K, Schraub S, Mercier M, Bontemps P. Role of alcohol and tobacco in the aetiology of head and neck cancer: a case-control study in the Doubs region of France. Eur J Cancer B Oral Oncol. 1995; 31B:301-9.

48. Wang Y, Zhai W, Wang H, Xia X, Zhang C. Benzo(a) pyrene promotes A549 cell migration and invasion through up-regulating Twist. Arch Toxicol. 2015; 89:451-8. https:// doi.org/10.1007/s00204-014-1269-8.

49. Fan CC, Wang TY, Cheng YA, Jiang SS, Cheng CW, Lee AY, Kao TY. Expression of E-cadherin, Twist, and p53 and their prognostic value in patients with oral squamous cell carcinoma. J Cancer Res Clin Oncol. 2013; 139:1735-44. https://doi.org/10.1007/s00432-013-1499-9.

50. Bass AJ, Thorsson V, Shmulevich I, Reynolds SM, Miller M, Bernard B, Hinoue T, Laird PW, Curtis C, Shen H, Weisenberger DJ, Schultz N, Shen R, et al, and Cancer Genome Atlas Research Network. Comprehensive molecular characterization of gastric adenocarcinoma. Nature. 2014; 513:202-9. https://doi.org/10.1038/ nature 13480 . 